\title{
A Rare Case of Anal and Perianal Chemical Burn in a Child due to Potassium Permanganate Crystals
}

\author{
Suvashis Dash $^{1}$ (1) $\cdot$ Jatin Bhojani $^{1} \cdot$ Sharadendu Sharma $^{1}$
}

Published online: 9 February 2018

(c) The Author(s) 2018. This article is an open access publication

\begin{abstract}
Many chemicals used as medical treatments can cause chemical burns as an untoward side effect. One of such chemicals is potassium permanganate. It is a caustic chemical used as a disinfectant. The most common sites of burn by potassium permanganate are exposed sites like the face and hands. Chemical burns in the perianal and anal region are rare in clinical practice and even sparser in the pediatric age group. In this article, we report a case of perianal and anal chemical burn in an 18-month-old, male child, caused by potassium permanganate crystal applied wrongly for the treatment of pinworm infestation. As a chemical burn in this region can have serious complications, it is necessary to be vigilant when using such chemicals in these cases. Early and timely management in such cases leads to good outcomes. This is the first of such cases of chemical burn caused by potassium permanganate in the anal and perianal region.
\end{abstract}

Suvashis Dash

suvashis.dash@gmail.com

1 Department of Burns, Plastic and Maxillofacial Surgery, Vardhman Mahavir Medical College and Safdarjung Hospital, H 2, First Floor, Green Park Main, New Delhi 110016, India

\section{Key Points}

Chemical burns in children are a rare entity.

Potassium permanganate, a caustic chemical, can cause chemical burns and can be catastrophic if systemically absorbed.

This article describes a case of anal and perianal chemical burn caused by potassium permanganate in a child.

\section{Introduction}

There are around 25,000 chemicals listed in the medical literature that can cause chemical burns. Potassium permanganate [International Union of Pure and Applied Chemistry (IUPAC) name potassium manganate (VII); chemical formula $\mathrm{KMnO}_{4}$ ] is a caustic chemical that can produce chemical burns. It is also known as permanganate of potash or Condy's crystals. It is mostly used as an antiseptic, disinfectant, or deodorizing agent. It is a strong oxidizing agent; because of which, it stains and causes chemical burns when it comes in contact with skin $[1,2]$. Chemical burns in the perianal area are uncommon, but they may lead to fatal complications and long-term sequelae like anal stenosis. Proximity to the anal canal predisposes patients to a greater chance of wound soiling and infection [3].

As for other chemical burns, early management involves copious irrigation, thorough wound care, and removal of 
devitalized tissue. The need for diverting colostomy in the management of these cases is still a topic of debate as it adds additional morbidity. Additional surgeries like diverting colostomy are accepted in adult cases, but in the pediatric population, these additional surgeries should be evaluated on a case-by-case basis [4].

The most important factor in the prognosis of the perianal burn is the depth of the burn, which in turn depends on the contact time and the strength of the chemical. Involvement of the anal canal and external genitalia adds to the complications caused by burns. One must be cautious to rule out internal injuries of the anal canal. Definitive management of these cases needs to be tailored to the requirements of the individual cases. As a general guideline, treatment should include identification of the involved structure and thorough debridement followed by wound coverage [5].

\section{Case Report}

An 18-month-old child presented with perianal burn at the burns casualty department of our hospital. The child's family was of low socioeconomic status and had gone to a local traditional healer 2 days earlier with complaints of worm infestation in the child. The healer had applied potassium permanganate crystals in the perianal area as well as inside the anal canal in a paste form. The child had no other co-morbidities, attained milestones as per age, and had been immunized adequately. There was no difficulty in voiding urine or passing stools. On examination, the child was afebrile, alert, actively crying, and had good hydration status. The child had a pulse rate of 106 beats per minute, blood pressure of $86 / 64 \mathrm{mmHg}$, and a respiratory rate of 26 breaths per minute. On inspection, the perianal region showed second degree superficial burns involving $1 \%$ total body surface area, which was stained black. Genital and gluteal areas were spared. Gentle examination of the anal region showed involvement of the lower anal area. There was no active bleeding from the wounds. No blood stains were found during passage of stool, as per information provided by the parents. Systemic examination including an abdominal examination did not reveal anything abnormal.

The wound was cleaned thoroughly and dressed with $1 \%$ silver sulfadizine cream, and the child was kept under observation on an outpatient basis. Blood investigations were found to be within normal limits. An ultrasonography of the abdomen and pelvis was done and was essentially normal. The child was managed on an outpatient basis. The child was afebrile during the course of conservative management. The child's wound epithelialized without any complications with application of multiple dressings within
2 weeks. After 5 months of follow-up, the child was passing stool normally and had no anal canal stenosis.

\section{Discussion}

Chemical burns account for 5-7\% of total burn admissions in burn centers [6]. They are mostly work related or homicide/assault-related in nature and involve exposed areas like the face, hands, and feet [7, 8].

Chemical burns caused by potassium permanganate are unusual. It is a very powerful oxidizing agent; it produces potassium hydroxide and manganese dioxide, which causes coagulative necrosis [2].

In the 1940s and 1950s, there were reports of vaginal burns caused by potassium permanganate when it was used as abortifacient [9].

Baron and Moss [10] reported a case of caustic burn involving a child's gluteal area. Riehemann et al. [11] reported a case of perianal burn in a 73-year-old lady caused by a potassium permanganate bath used for the treatment of psoriasis. Cartotto et al. [12] reported one case of chemical burn caused by potassium permanganate.

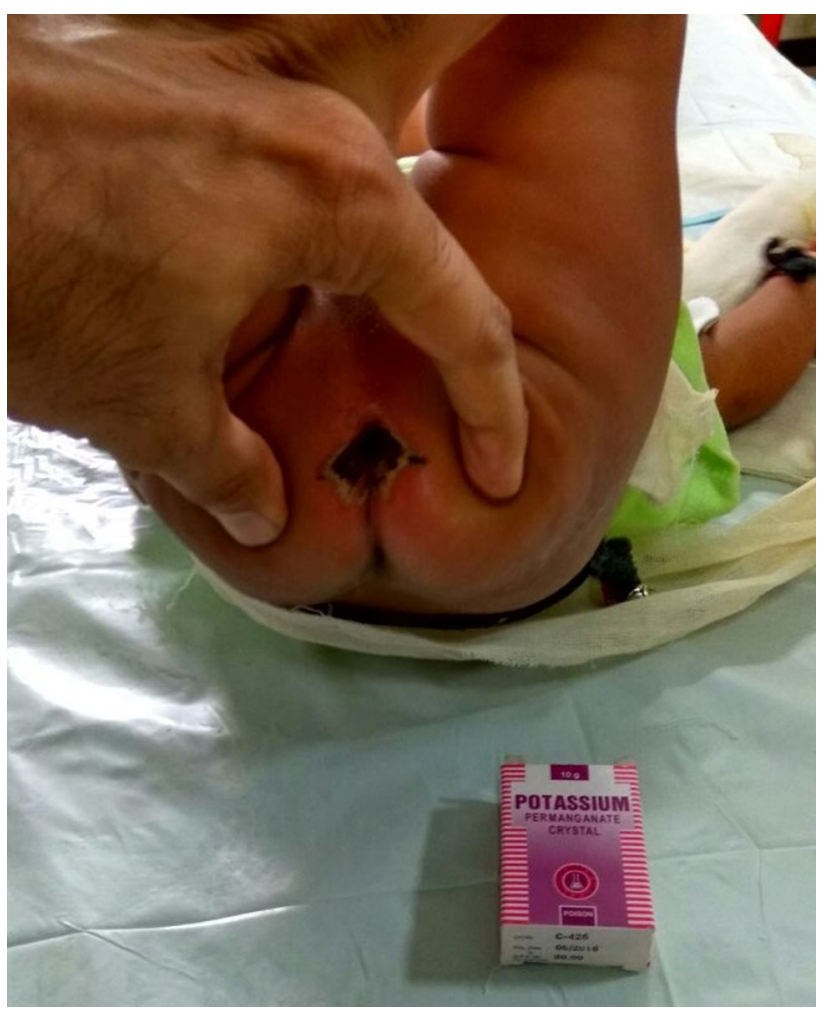

Fig. 1 Perianal area of the child showing burn wound with blackish discoloration caused by potassium permanganate chemical burn. The picture also shows the packet from which the potassium permanganate was used 
There are several case reports of accidental ingestion of potassium permanganate reported in the literature leading to oral mucosa burns, gastric mucosa injury, hemorrhagic pancreatitis, hepatorenal failure, methaemoglobinaemia, and hepatic failure [10-20]. Many cases of ocular burn have also been reported [21].

Patients with systemic toxicity manifest with acute respiratory distress syndrome (ARDS), coagulopathy, pancreatitis, and hepatic failure [16-19]. According to published literature, potassium permanganate's systemic toxicity profile is similar to acetaminophen toxicity [18]. Many authors have treated systemic manifestations with $\mathrm{N}$-acetyl cysteine [18].

Mahomedy et al. [22] reported a case manifesting with systemic toxicity due to potassium permanganate, and the patient was successfully treated with methylene blue and vitamin $\mathrm{C}$, leading to an uneventful recovery (Fig. 1).

\section{Conclusion}

Potassium permanganate as a cause of chemical burn is uncommon. Such chemicals when used for medicinal purposes should be used with utmost care. Systemic toxicity may be caused by ingestion or systemic absorption. Early and prompt management is needed for recovery.

\section{Compliance with Ethical Standards}

Conflict of interest Suvashis Dash, Jatin Bhojani, and Sharadendu Sharma declare that they have no conflict of interest.

Funding No financial support was received for the preparation of the manuscript.

Consent Written informed consent was obtained from the patient's parents for publication of this case report and for inclusion of the accompanying image.

Open Access This article is distributed under the terms of the Creative Commons Attribution-NonCommercial 4.0 International License (http://creativecommons.org/licenses/by-nc/4.0/), which permits any noncommercial use, distribution, and reproduction in any medium, provided you give appropriate credit to the original author(s) and the source, provide a link to the Creative Commons license, and indicate if changes were made.

\section{References}

1. The National Institute for Occupational Safety and Health (NIOSH) website https://www.cdc.gov/niosh/ipcsneng/neng0672. html. Accessed 2 Feb 2017.

2. Potassium permanganate https://en.wikipedia.org/wiki/Potassium permanganate\#cite_note-pmid12282068-7. Accessed 7 Feb 2017.
3. Bordes J, Le Floch R, Bourdais L, Gamelin A, Lebreton F, Perro G. Perineal burn care: French working group recommendations. Burns. 2014;40(4):655-63.

4. Price CE, Cox S, Rode H. The use of diverting colostomies in paediatric peri-anal burns: experience in 45 patients. S Afr J Surg. 2013;51(3):102-5.

5. Merchant N, Boudana D, Willoughby L, Lin J, Rehou S, Shahrokhi S, et al. Management of adult patients with buttock and perineal burns: the Ross Tilley Burn Centre experience. J Trauma Acute Care Surg. 2014;77(4):640-8.

6. Orr MF, Sloop S, Wu J. Acute chemical incidents surveillanceHazardous Substances Emergency Events Surveillance, nine states, 1999-2008. CDC. Hazardous Substances Emergency Events Surveillance, nine states. 1999;2008.

7. Akhtar MS, Ahmad I, Khurram MF, Kanungo S. Epidemiology and outcome of chemical burn patients admitted in Burn Unit of JNMC Hospital, Aligarh Muslim University, Aligarh, Uttar Pradesh, India: a 5-year experience. J Fam Med Prim Care. 2015;4(1):106.

8. Agbenorku P, Akpaloo J, Chirurgie F, Aboah K, Klutsey E, Hoyte-Williams PE. et al Chemical burn injury in Kumasi: the trend and complications following and their management. Plast Reconstr Surg Glob Open. 2015;3(10):e548.

9. Carney BH. Vaginal burns from potassium permanganate. Am J Obstet Gynecol. 1953;65(1):127-30.

10. Baron S, Moss C. Caustic burn caused by potassium permanganate. Arch Dis Child. 2003;88:96.

11. Riehemann AC, Körber A, Voshege N, Schadendorf D, Dissemond J. Perianal ulcerations caused by potassium permanganate bath. Der Hautarzt; Zeitschrift fur Dermatologie, Venerologie, und verwandte Gebiete. 2010;61(5):435-8.

12. Cartotto RC, Peters WJ, Neligan PC, et al. Chemical burns. Can J Surg. 1996;39:205-11.

13. Sachs HB, Shamoun E. Chemical burns of the female genitalia after use of potassium permanganate. Zentralbl Gynakol. 1961;83:459-63.

14. Younan L, Eloubeidi M, Barada K. A rare cause of caustic gastric injury in a young man. Gastroenterology. 2013;145(1):259.

15. Ivanov AP, Miroshnikov BI, Iakunin SI, Pavlov PV, Kopiakov AL, Galkina NV. Esophagoplasty in combined scarry lesions of the esophagus, laryngopharynx and the trachea in children. Vestnik khirurgii imeni II Grekova. 2012;172(5):59-65.

16. Johnson TB, Cassidy DD. Unintentional ingestion of potassium permanganate. Pediatr Emerg Care. 2004;20:185-7.

17. Lustig S, Pitlik SD, Rosenfeld JB. Liver damage in acute selfinduced hypermanganemia. Arch Intern Med. 1982;142:405-6.

18. Young RJ, Critchley JA, Young KK, Freebairn RC, Reynolds AP, Lolin YI. Fatal acute hepatorenal failure following potassium permanganate ingestion. Hum Exp Toxicol. 1996;15:259-61.

19. Dhamrait RS. Airway obstruction following potassium permanganate ingestion. Anaesthesia. 2003;58:606-7.

20. Middleton SJ, Jacyna M, McClaren D, Robinson R, Thomas HC. Haemorrhagic pancreatitis - a cause of death in severe potassium permanganate poisoning. Postgrad Med J. 1990;66:657-8.

21. Sigg T, Leikin JB, Sigg K, Mullin T. Treatment of ocular potassium permanganate exposure with $5 \%$ ascorbic acid solution. Ann Emerg Med. 1998;32(6):754-5.

22. Mahomedy MC, Mahomedy YH, Canham PA, Downing JW, Jeal DE. Methaemoglobinaemia following treatment dispensed by witch doctors. Two cases of potassium permanganate poisoning. Anaesthesia. 1975;30:190-3. 